\title{
AGREGAÇÃO DE UM ARGISSOLO SOB POMAR DE GOIABEIRAS APÓS APLICAÇÃO DE RESÍDUOS DA INDÚSTRIA PROCESSADORA DE GOIABA ${ }^{1}$
}

\author{
GETULIO DE FREITAS SEBEN JUNIOR ${ }^{2}$, FERNANDO KUHNEN ${ }^{3}$, \\ THIAGO DE BARROS SYLVESTRE ${ }^{4}$, CINARA XAVIER DE ALMEIDA ${ }^{5}$, \\ JOSÉ FREDERICO CENTURION ${ }^{6}$
}

RESUMO - A utilização de resíduos da indústria de processamento de frutas na agricultura pode proporcionar melhorias à qualidade do solo. Dessa forma, objetivou-se com este estudo avaliar o efeito da aplicação de resíduos de sementes de goiaba na agregação e no estoque de carbono orgânico do solo (EC). O experimento esteve inserido em um pomar comercial irrigado de goiabeiras (cv. Paluma), com sete anos de idade, sobre um Argissolo Vermelho-Amarelo distrófico típico. O delineamento experimental foi em blocos casualizados e parcelas subdivididas, sendo cinco tratamentos (doses de: 0;9;18;27 e $36 \mathrm{Mg}_{\mathrm{ga}}^{-1}$ de resíduo) e duas camadas de solo $(0-0,10$ e 0,10-0,20 m). Foi avaliado o mesmo tipo de solo sobre mata nativa adjacente à área experimental. As análises realizadas foram a distribuição do tamanho dos agregados estáveis em água, o diâmetro médio ponderado, o diâmetro médio geométrico, os agregados maiores que 2 mm e o EC. Os dados foram submetidos à análise de variância (Teste F), seguindo o delineamento em blocos casualizados com parcelas subdivididas ( 5 doses $\mathrm{x} 2$ camadas). As médias dos tratamentos foram comparadas pelo teste de Tukey, a 5\% de probabilidade, e as médias das camadas foram comparadas pelo teste F, a 5\% de probabilidade. Os dados coletados no solo sob mata foram utilizados apenas como referência de um solo em estado natural e, portanto, não foram considerados como fator de variação nas análises de variância. Os valores dos índices de agregação com o estoque de carbono orgânico do solo foram submetidos à correlação de Pearson $(\mathrm{p} \leq 0,05)$. O efeito das doses de resíduo de sementes de goiaba sobre o estoque de carbono orgânico, na camada de 0-0,20 m do solo, foi avaliado por análise de regressão. Os tratamentos não diferiram em relação à agregação do solo, contudo EC foi diretamente relacionado à quantidade de resíduo aplicado ao solo. Houve correlação positiva e significativa entre os índices de agregação e o EC. A aplicação de resíduos de sementes de goiaba proporcionou melhoria da qualidade do solo.

Termos para indexação: agregação, estrutura do solo, estoque de carbono do solo.

\section{AGGREGATION OF AN ULTISSOL UNDER GUAVA ORCHARD AFTER APPLICATION OF ORGANIC GUAVA-PROCESSING INDUSTRY RESIDUES}

\begin{abstract}
The use of industrial residues from fruit processing in agriculture can provide improvements to soil quality. Thus, the aim of this study was to evaluate the effect of residues of guava seeds on soil aggregation and soil organic carbon stock (SOC). The experiment was inserted in an irrigated orchard of guava trees (cv. Paluma) seven years old on a Red-Yellow Ultissol. The experimental design was randomized block and split plot with five treatments (doses: $0,9,18,27$ and $36 \mathrm{Mg} \mathrm{ha}^{-1}$ of residue) and two soil layers (0.00 to 0.10 and 0.10 to $0.20 \mathrm{~m}$ ). It was evaluated the same type of soil on a native forest adjacent to the experimental area. It was analyzed the size distribution of water stable aggregates, the average diameter, the geometric mean diameter, aggregates larger than $2 \mathrm{~mm}$ and SOC. Data were subjected to analysis of variance (F test) following a randomized complete block design with split-plot ( $5 \times 2$ layers). The treatment means were compared by Tukey test at 5\% probability and the average of the layers were compared by $\mathrm{F}$ test at $5 \%$ probability. The data collected in the forest soil were used only as a reference soil in natural state and therefore were not considered as a factor of variation in the analysis of variance. The values of aggregation index with the soil organic carbon stock were subjected to Pearson correlation $(\mathrm{p} \leq 0.05)$. The effect of residual doses of guava seeds on the soil organic carbon from 0.00 to $0.20 \mathrm{~m}$ of soil layer was evaluated by regression analysis. The treatments did not differ in relation to soil aggregation; however, SOC was directly related to the amount of residues applied to the soil. There was significant positive correlation between aggregation index and SOC. The application of residues from guava seeds provided an improvement of soil quality.

Index terms: aggregates, soil structure, soil organic carbon.

\footnotetext{
'(Trabalho 020-11). Recebido em: 04-01-2011. Aceito para publicação em: 10-08-2011.

${ }^{2}$ Doutorando do Curso de Pós-Graduação em Agronomia, Universidade Estadual Paulista “Júlio de Mesquita Filho”, Campus de Jabo-

${ }^{3}$ Doutorando do Curso de Pós-Graduação em Agronomia, FCAV/UNESP. Bolsista CAPES. E-mail: f_kuhnen@hotmail.com

${ }^{4}$ Doutorando do Curso de Pós-Graduação em Agronomia, FCAV/UNESP. Bolsista CAPES. E-mail: thiagosylvestre@hotmail.com

${ }^{5}$ Doutoranda do Curso de Pós-Graduação em Agronomia, FCAV/UNESP. Bolsista FAPESP. E-mail: cinarax@yahoo.com.br
} ticabal - FCAV/UNESP, Jaboticabal-SP, CEP: 14884-418. Bolsista CAPES. E-mail: getulioseben@yahoo.com.br

${ }^{6}$ Professor Adjunto, FCAV/UNESP. Bolsista CNPq. E-mail: jfcentur@fcav.unesp.br
\end{abstract}




\section{INTRODUÇÃO}

No município de Vista Alegre do Alto-SP, o cultivo de goiabeira destaca-se favorecido pelas condições climáticas e pela ocorrência dos Argissolos. Na camada superficial desses solos, as raízes das plantas encontram ótimas condições de aeração para o seu crescimento; já na camada subjacente, encontram maiores teores de argila, onde ficam retidos a água e os nutrientes essenciais para o seu desenvolvimento e, consequentemente, para a produtividade dessas plantas.

Atraídas pela produção de hortifrutis, várias indústrias de beneficiamento instalaram-se no município. As indústrias geram renda e emprego à cidade, no entanto a produção de resíduos orgânicos e o destino destes podem tornar-se um problema ambiental. Por outro lado, a sustentabilidade dos pomares está diretamente relacionada com o teor e a qualidade da matéria orgânica presente no solo. A redução dos teores de matéria orgânica pode ser dada: por ação do processo erosivo que carreia as partículas; pela irrigação, que pode acelerar o processo de decomposição da matéria orgânica, e pela poda das plantas, que exporta material orgânico para fora da área, diminuindo a ciclagem de nutrientes.

A adição de resíduos orgânicos, oriundos da indústria processadora de goiabas, pode ser uma fonte viável de repor as perdas de matéria orgânica do solo. A matéria orgânica proporciona melhorias às condições estruturais do solo, além de disponibilizar nutrientes que possam suprir total ou parcialmente as necessidades das plantas, diminuindo os custos de produção dos produtores, com aquisição de adubo químico. Leonel e Damatto Júnior (2008) relataram que a aplicação de esterco de curral curtido (39\% MO) ao solo supriu as exigências nutricionais da cultura da figueira, indicando resultados positivos com relação à produção de frutos.

No solo, a adição de matéria orgânica contribui para a diminuição dos valores de densidade (VASCONCELOS et al., 2010) e para a formação e estabilidade dos agregados (MARTINS et al., 2009). A agregação do solo tem sido utilizada como um indicador da qualidade estrutural do solo (SALTON et al., 2008). O comportamento da estrutura do solo é fundamental para compreender a dinâmica dos movimentos internos de água, ar e calor, e, também, o crescimento das raízes (VASCONCELOS et al., 2010).

A avaliação das propriedades físicas do solo (estrutura), por meio de seus agregados, é recomendada para o monitoramento ambiental dos recursos naturais, pelas normas técnicas específicas para a produção integrada de goiaba - NTEPI-Goiaba, e amparada pela instrução normativa/sdc, $\mathrm{n}^{\circ} 07$, de 11 de novembro de 2005.

As consequências da utilização dos resíduos sobre os recursos naturais não renováveis, solo e água, estão sendo alvos de muitos estudos no município. Estes estudos têm muita importância prática, pois servem de embasamento científico para que os produtores possam adotar os valores ideais e/ou terem conhecimento dos valores-limite da quantidade de resíduos adicionados ao solo.

Sendo assim, a hipótese estudada foi a de que o uso de resíduos provenientes do beneficiamento da goiaba pode favorecer a estrutura do solo. O objetivo deste estudo foi avaliar o efeito da aplicação de diferentes doses de resíduos de sementes de goiaba na agregação e no estoque de carbono orgânico do solo.

\section{MATERIAL E MÉTODOS}

A área experimental constitui parte de um talhão comercial de goiabeiras, localizado na maior região produtora de frutas do Estado de São Paulo, município de Vista Alegre do Alto, com coordenadas geográficas $21^{\circ} 15^{\prime}$ sul, $48^{\circ} 18^{\prime}$ oeste e altitude de 603 m. Segundo a classificação de Köeppen, o clima local é do tipo Cwa, subtropical com inverno curto, moderado e seco, verão quente e chuvoso, caracterizando duas estações distintas. O solo da área é um Argissolo Vermelho-Amarelo distrófico típico, textura arenosa/média.

O pomar irrigado de goiabeiras (Psidium guajava L.), cultivar Paluma, com idade de sete anos, é espaçado de 7 x $5 \mathrm{~m}$ e recebeu controle fitossanitário para pragas, doenças e plantas infestantes, sempre que necessário. Uma amostragem do solo, antes da aplicação dos tratamentos, foi realizada para fins de caracterização da fertilidade, segundo Raij et al. (2001).

$O$ resultado da análise anterior ao experimento, na camada de $0-0,20 \mathrm{~m}$,mostrou: $\mathrm{pH}=5,3 ; \mathrm{MO}$ $=11 \mathrm{~g} \mathrm{dm}^{-3} ; \mathrm{P}$ (resina) $=8 \mathrm{mg} \mathrm{dm}^{-3} ; \mathrm{S}^{-\mathrm{SO}_{4}}{ }^{-2}=1 \mathrm{mg}$ $\mathrm{dm}^{-3}$; e $\mathrm{K}, \mathrm{Ca}, \mathrm{Mg}$ e $\mathrm{H}+\mathrm{AL}$ iguais a 2,7; 18; 6 e 16 $\mathrm{mmol}_{\mathrm{c}} \mathrm{dm}^{-3}$, respectivamente. Foi realizada, ainda, a análise do resíduo, que apresentou o seguinte resultado: $\mathrm{C}, \mathrm{N}, \mathrm{P}, \mathrm{K}, \mathrm{Ca}, \mathrm{Mg}$ e $\mathrm{S}$ foram iguais a $345 ; 11,6$; 2,$2 ; 2,3 ; 0,8 ; 0,9$ e $1,3 \mathrm{~g} \mathrm{~kg}^{-1}$, respectivamente. Os teores dos micronutrientes $\mathrm{B}, \mathrm{Cu}, \mathrm{Fe}, \mathrm{Mn}$ e $\mathrm{Zn}$ foram iguais a $10 ; 10 ; 150 ; 12$ e $8 \mathrm{mg} \mathrm{kg}^{-1}$, respectivamente.

O delineamento experimental foi o de blocos casualizados, com parcelas subdivididas, sendo cinco tratamentos: ausência (testemunha) e aplicação de um resíduo proveniente da indústria processadora de polpas e conservas, que é composto basicamente de 
sementes moídas de goiaba, nas doses de: 9; 18;27 e $36 \mathrm{Mg} \mathrm{ha}^{-1}$ (peso seco), e duas camadas de solo (0-0,10 e 0,10-0,20 m). As doses equivalem, respectivamente, à adição de 3,$11 ; 6,21 ; 9,32$ e $12,42 \mathrm{Mg}$ $\mathrm{ha}^{-1}$ de carbono. As parcelas experimentais foram constituídas por cinco plantas, correspondendo a uma área total de $175 \mathrm{~m}^{2}$ e área útil de $105 \mathrm{~m}^{2}$, sendo que as três goiabeiras centrais foram consideradas como área útil para realizar as avaliações, e as duas das extremidades, consideradas bordadura. Uma área sob mata nativa adjacente ao experimento foi amostrada,e os dados foram utilizados apenas como referência de um solo em estado de equilíbrio.

As doses foram estabelecidas em função do teor de nitrogênio no resíduo e baseadas nas exigências nutricionais da goiabeira em nitrogênio, na idade das plantas e na produtividade de $60 \mathrm{Mg} \mathrm{ha}^{-1}$ de frutos por safra (NATALE et al., 1996). O resíduo foi aplicado manualmente, sobre a superfície do solo e na projeção da copa das plantas de cada parcela. A primeira aplicação do resíduo foi realizada durante a implantação do experimento, em março de 2006, e as demais aplicações ocorreram sempre nos meses de janeiro dos anos de 2007, 2008, 2009 e 2010.

A coleta das amostras de solo foi realizada em março de 2010, nas camadas de 0-0,10 e 0,10$0,20 \mathrm{~m}$ de profundidade. Os agregados do solo com diâmetro entre 7,93-4,00 mm, obtidos por meio do peneiramento de amostras indeformadas de solo secas ao ar, foram avaliados quanto à estabilidade de agregados via úmida, conforme Kemper e Chepil (1965). Para isso, foram utilizados $50 \mathrm{~g}$ de agregados pré-umedecidos em peneiras com abertura de malha de 4,$00 ; 2,00 ; 1,00 ; 0,50 ; 0,25$ e $0,125 \mathrm{~mm}$ e um aparelho de oscilação vertical ajustado para 31 ciclos min $^{-1}$, com amplitude de oscilação de $35 \mathrm{~mm}$, durante 15 minutos. A análise de agregados foi realizada em quadruplicatas, e os resultados foram expressos em porcentagem de agregados retidos em cada classe, agregados maiores que $2,00 \mathrm{~mm}$, diâmetro médio ponderado (DMP) e diâmetro médio geométrico (DMG), conforme Kemper e Chepil (1965). O conteúdo de areia presente nas classes de agregados não foi descartado, uma vez que essas partículas participam do processo de agregação do solo (CASTRO FILHO et al., 1998). Foi determinado, ainda, o estoque de carbono orgânico pelo método de camadas equivalentes de solo (BAYER et al., 2006).

Os dados foram submetidos à análise de variância (Teste F) seguindo o delineamento em blocos casualizados, com parcelas subdivididas (cinco doses $\mathrm{x}$ duas camadas). As médias dos tratamentos foram comparadas pelo teste de Tukey, a 5\% de probabilidade, e as médias das camadas foram comparadas pelo teste $\mathrm{F}$, a $5 \%$ de probabilidade. Os dados coletados no solo sob mata foram utilizados apenas como referência de um solo em estado natural e, portanto, não foram considerados como fator de variação nas análises de variância. Os valores dos índices de agregação com o estoque de carbono orgânico do solo foram submetidos à correlação de Pearson $(p \leq 0,05)$. O efeito das doses de resíduo de sementes de goiaba sobre o estoque de carbono orgânico na camada de 0-0,20 $\mathrm{m}$ do solo foi avaliado por análise de regressão.

\section{RESULTADOS E DISCUSSÃO}

As doses do resíduo não proporcionaram diferenças entre os tratamentos, para a distribuição dos agregados em classes de tamanho (Quadro 1). A aplicação do resíduo de sementes de goiaba não influenciou no tamanho dos agregados do solo, uma vez que a testemunha foi a que apresentou agregados maiores, mais semelhantes à condição de solo em estado natural (sob mata nativa). Resultados semelhantes foram obtidos por Loss et al. (2009) ao compararem o efeito de sistemas de manejo sobre os atributos físicos de um Argissolo Vermelho-Amarelo, verificando que o cultivo de Figo (sete anos), que recebeu adubação orgânica com esterco bovino (no plantio) e esterco de aviário (em cobertura), não proporcionou diferenças na agregação do solo em comparação com um sistema agroflorestal. Conforme os autores, a adubação orgânica torna disponíveis elementos como $\mathrm{N}$ e $\mathrm{C}$, os quais propiciam melhor desenvolvimento do sistema radicular das culturas, que, por sua vez, proporcionam a agregação do solo. O sistema radicular das plantas e a agregação do solo apresentam estreita relação (ÁLVARO-FUENTES et al., 2008).

Não foi constatada interação entre os tratamentos e as camadas de solo. Entre as camadas de solo, os agregados maiores que 4,00 mm e os índices de agregação (DMP, DMG e agregados maiores que $2,00 \mathrm{~mm}$ ) apresentaram maiores valores na camada de 0-0,10 m, em comparação com a camada subjacente (Quadro 2), e o contrário foi verificado para as demais classes de tamanhos de agregados (Quadro 1), em função da camada de solo, devido à maior quantidade de agregados maiores, retidos na peneira com maior abertura de malha. A presença de agregados maiores e mais estáveis na camada superficial do solo é importante para a resistência estrutural do solo à ação de forças erosivas e indica que a matéria orgânica do solo e o sistema radicular da goiabeira foram mais importantes do que o aumento do teor de argila em profundidade, característico dos 
Argissolos.

Assim como as raízes das plantas influenciam na qualidade física do solo, por meio da agregação, o solo também influencia no desenvolvimento das plantas. Sorrenti et al. (2008) avaliaram o efeito de adubos orgânicos de diferentes origens sobre o desenvolvimento inicial de plantas de tangerineira. Esses autores verificaram que a adição de um composto orgânico supriu as necessidades das plantas em nutrientes e proporcionou os maiores parâmetros biométricos às plantas. Da mesma forma, Kusdra et al. (2008), ao avaliarem o efeito da adição de doses de coprólitos de minhoca em um solo distrófico, para produção de mudas de mamoeiro, verificaram efeito positivo sobre o crescimento da parte aérea e do sistema radicular das plantas, proporcionado pelo aumento dos teores de matéria orgânica, $\mathrm{Ca}$ e Mg. Estes elementos são considerados agentes floculantes e atuam na agregação do solo.

Para o diâmetro médio ponderado (DMP), o diâmetro médio geométrico (DMG) e a porcentagem de agregados maiores que $2,00 \mathrm{~mm}$, não diferiram entre os tratamentos nem com a mata (Quadro 2). Esses resultados inferem que a adição de resíduos orgânicos está contribuindo para a formação de agregados estáveis e de maior tamanho, devido à adição de matéria orgânica, comportando-se semelhantemente ao que ocorre na mata; entretanto, a matéria orgânica na mata é originada da ciclagem de nutrientes pela decomposição da serapilheira. A matéria orgânica é reconhecidamente um agente aglutinador das partículas primárias do solo, resultando na melhoria da qualidade do solo (SALTON et al., 2008).

Entretanto, Cardozo et al. (2008) verificaram que a adubação orgânica proporcionou maiores valores de agregação para as camadas de $0-0,05$ e 0,05-0,10 m em comparação com a floresta secundária, após terem comparado um sistema de produção orgânica há 13 anos (aplicação de: torta de mamona, farinha de osso, esterco de aviário, calcário e fosfato de rocha) com uma área adjacente composta de floresta, ambas sob um Argissolo Vermelho-Amarelo. Com os resultados, esses autores chamaram a atenção para a importância do fornecimento de resíduos orgânicos na manutenção da agregação.

Por outro lado, Matos et al. (2008) relataram maiores valores de DMP e DMG em um Argissolo Vermelho-Amarelo, proporcionados por uma mata (floresta atlântica) em comparação com a adubação orgânica (resíduos de soja, feijão e esterco bovino) e a adubação mineral. Os autores atribuíram o resultado ao acúmulo de matéria orgânica do solo.
Foram verificadas correlações significativas, a $1 \%$ de probabilidade, entre o estoque de carbono orgânico do solo, na camada de 0-0,20 m, com o DMP, com o DMG e com os valores de agregados maiores que 2,00 mm (Figura 1). O carbono é um dos constituintes da matéria orgânica do solo, que proporciona a agregação do solo, daí a correlação entre eles. No entanto, o grau de correlação entre o carbono e a agregação depende do clima, tipo de solo, textura e mineralogia (MATOS et al., 2008).

Os maiores estoques de carbono orgânico foram verificados no solo sob mata nativa em comparação com os tratamentos. O estoque de carbono no solo sob mata nativa foi 2,7 vezes maior que o tratamento em que não foi aplicado resíduo ao solo, evidenciando a importância do aporte de resíduos vegetais ao solo, sob condições naturais. A diminuição do estoque de carbono orgânico verificada nos solos sob cultivo pode ser atribuída ao aumento do consumo de carbono prontamente disponível pela biomassa microbiana e, ainda, pelo sistema de produção e manejo adotados. Ao avaliar a qualidade da camada superficial do solo, Souza et al. (2009) relataram diminuição dos estoques de carbono com a intensidade de utilização do solo.

Ao serem comparados apenas os tratamentos, verifica-se que a dose de $27 \mathrm{Mg} \mathrm{ha}^{-1}$ proporcionou ao solo o maior valor de estoque de carbono em comparação com a testemunha e a dose de $9 \mathrm{Mg}$ ha ${ }^{1}$, entretanto não diferiu das demais doses de resíduo aplicados ao solo. Dentre as camadas de solo analisadas, independentemente do tratamento, os maiores estoques de carbono foram encontrados na camada de 0-0,10 em comparação com a camada de $0,10-0,20$ $\mathrm{m}$. A aplicação de resíduo de sementes de goiaba foi importante não só para a melhoria da qualidade do solo, como também constitui uma importante fonte no sequestro de carbono, já que o solo, constitui a maior reserva desse elemento (GATTO et al., 2010), exercendo, dessa forma, papel fundamental sobre a emissão de gases de efeito estufa e consequentes mudanças climáticas globais (CARVALHO et al., 2010). Segundo esses pesquisadores, o aumento da capacidade dos solos no sequestro de carbono pode ser uma contrapartida para amenizar os efeitos do gás carbônico atmosférico proveniente principalmente da queima de combustíveis fósseis, do desmatamento e do uso inadequado do solo para a agricultura, diminuindo, assim, os impactos ambientais por ele provocados.

Observa-se que o estoque de carbono orgânico foi diretamente relacionado à quantidade de resíduo aplicado ao solo (Figura 2). Dessa forma, quanto maior for a quantidade de resíduo aplicada, maior será a incorporação de carbono ao solo. Corrêa et al. 
(2005), citado por Souza et al. (2011), verificaram que o teor de matéria orgânica e o teor de K aumentaram linearmente com as doses deste mesmo resíduo aplicados a um Argissolo Vermelho-Amarelo, em condições de laboratório.

TABELA 1 - Porcentagem de agregados estáveis em água por classe de diâmetro em camadas de um Argissolo Vermelho-Amarelo sob mata nativa e pomar de goiabeiras após a aplicação de doses de resíduo de sementes de goiaba.

\begin{tabular}{|c|c|c|c|c|c|c|}
\hline \multirow{2}{*}{ Tratamentos $(\mathrm{T})$} & \multicolumn{6}{|c|}{ Classes de agregados (mm) } \\
\hline & $>4$ & $4-2$ & $2-1$ & $1-0,5$ & $0,5-0,25$ & $<0,25$ \\
\hline Mata $^{(1)}$ & 99,4 & 0,4 & 0,1 & 0,1 & 0,1 & 0,0 \\
\hline $0 \mathrm{Mg} \mathrm{ha}^{-1}$ & 96,4 & 2,1 & 0,7 & 0,4 & 0,3 & 0,1 \\
\hline $9 \mathrm{Mg} \mathrm{ha}^{-1}$ & 95,1 & 2,6 & 0,9 & 0,7 & 0,6 & 0,1 \\
\hline $18 \mathrm{Mg} \mathrm{ha}^{-1}$ & 95,4 & 2,2 & 1,1 & 0,8 & 0,5 & 0,1 \\
\hline $27 \mathrm{Mg} \mathrm{ha}^{-1}$ & 93,1 & 3,5 & 1,8 & 0,9 & 0,6 & 0,2 \\
\hline $36 \mathrm{Mg} \mathrm{ha}^{-1}$ & 92,1 & 5,7 & 1,0 & 0,6 & 0,5 & 0,1 \\
\hline Teste F & $1,42^{\mathrm{ns}}$ & $1,24^{\mathrm{ns}}$ & $1,30^{\mathrm{ns}}$ & $0,94^{\mathrm{ns}}$ & $1,15^{\mathrm{ns}}$ & $1,58^{\mathrm{ns}}$ \\
\hline $\mathrm{CV}(\%)$ & 6,4 & 27,4 & 10,9 & 12,3 & 10,3 & 9,3 \\
\hline \multicolumn{7}{|l|}{ Camadas $(\mathrm{C})$} \\
\hline $0-0,10 \mathrm{~m}$ & $98,0 \mathrm{a}$ & $1,2 \mathrm{~b}$ & $0,4 \mathrm{~b}$ & $0,2 \mathrm{~b}$ & $0,2 \mathrm{~b}$ & $0,0 \mathrm{~b}$ \\
\hline $0,10-0,20 \mathrm{~m}$ & $92,5 \mathrm{~b}$ & $4,4 \mathrm{a}$ & $1,5 \mathrm{a}$ & $0,9 \mathrm{a}$ & $0,6 \mathrm{a}$ & $0,1 \mathrm{a}$ \\
\hline Teste F & $11,75^{* *}$ & $6,09^{* *}$ & $12,51^{* *}$ & $16,13^{* *}$ & $10,86^{* *}$ & $10,45^{* *}$ \\
\hline CV (\%) & 5,8 & 27,5 & 9,4 & 8,9 & 8,4 & 7,5 \\
\hline \multicolumn{7}{|l|}{ TX C } \\
\hline Teste F & $1,84^{\mathrm{ns}}$ & $1,53^{\mathrm{ns}}$ & $1,84^{\mathrm{ns}}$ & $1,55^{\mathrm{ns}}$ & $0,99^{\text {ns }}$ & $1,12^{\mathrm{ns}}$ \\
\hline
\end{tabular}

${ }^{(1)}$ Os dados coletados no solo sob mata nativa não foram utilizados para a análise estatística, apenas tidos como referência. ${ }^{\text {ns }}$ não diferiram a $5 \%$ de probabilidade e, ${ }^{* *}$ médias seguidas por letras minúsculas diferentes, na coluna, diferiram a $5 \%$ de probabilidade e referem-se à comparação de camadas de um mesmo tratamento.

TABELA 2 - Índices de agregação em camadas de um Argissolo Vermelho-Amarelo sob mata nativa e pomar de goiabeiras após a aplicação de doses de resíduo de sementes de goiaba

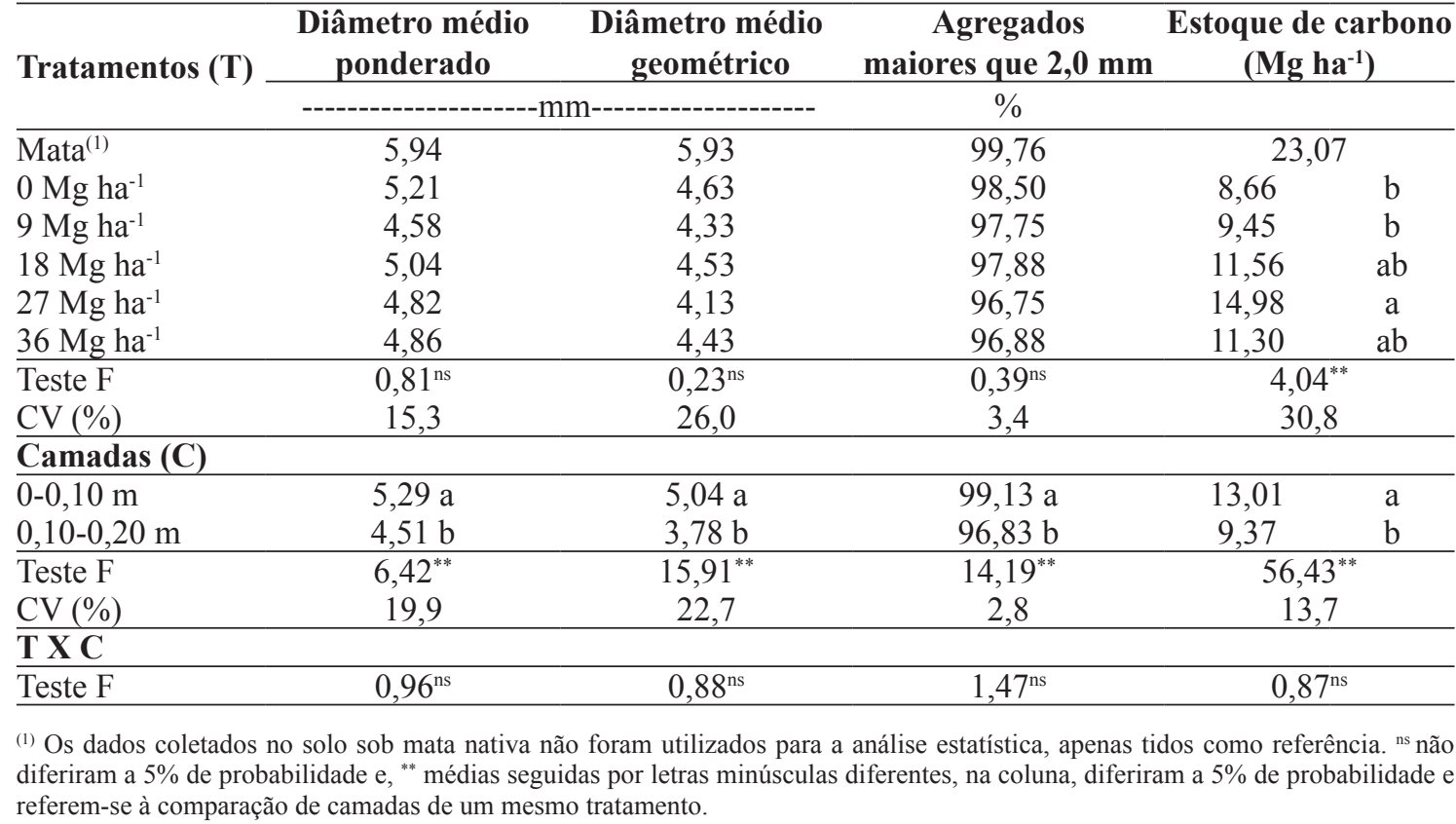



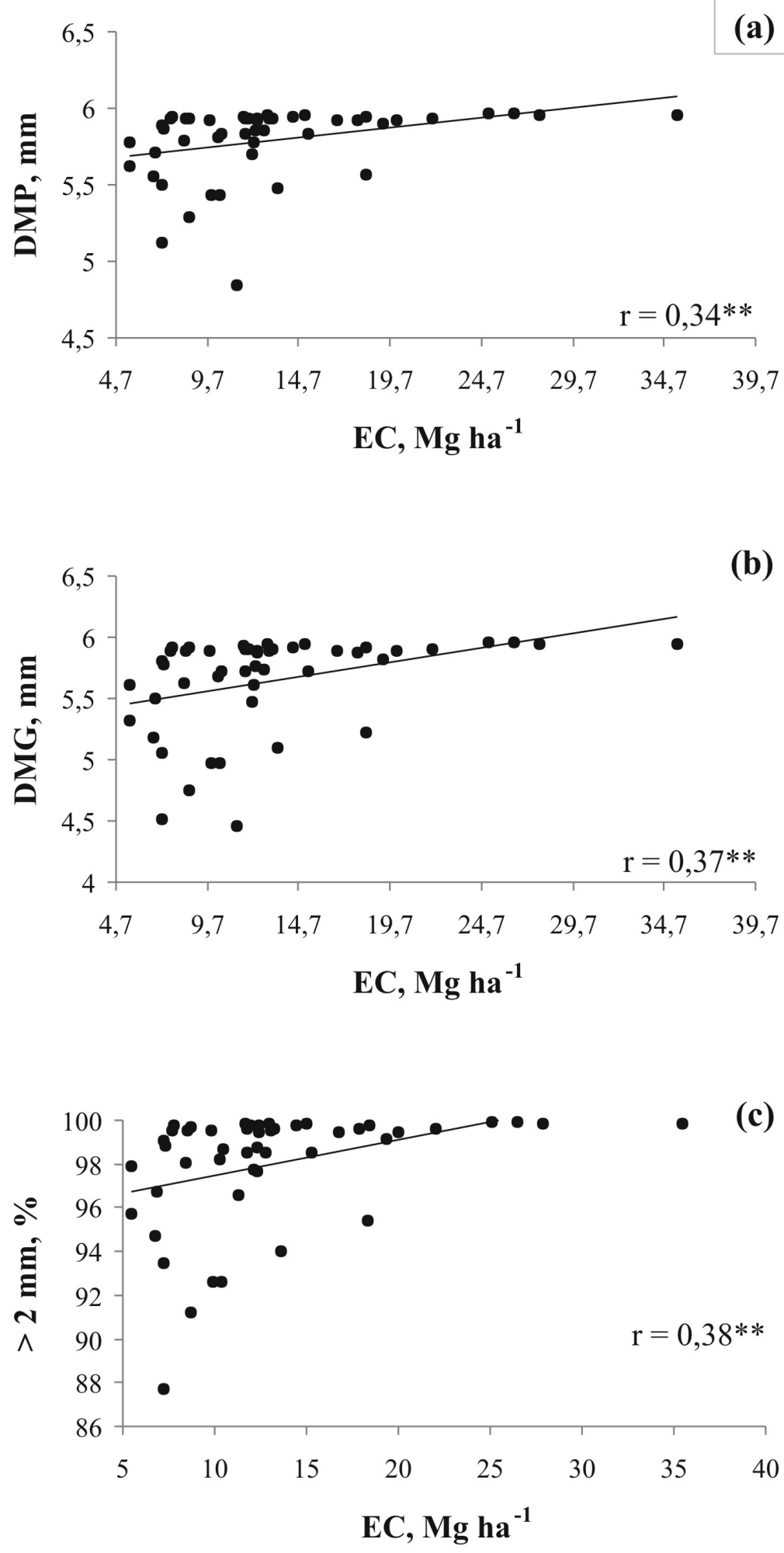

FIGURA 1 - Correlação entre: (a) o diâmetro médio ponderado (DMP); (b) o diâmetro médio geométrico (DMG); (c) a porcentagem de agregados maiores que 2,00 $\mathrm{mm}$ e o estoque de carbono orgânico (EC), na camada de 0-0,20 m, de um Argissolo Vermelho-Amarelo distrófico sob pomar de goiabeiras após a aplicação de doses de resíduo de sementes de goiaba. 


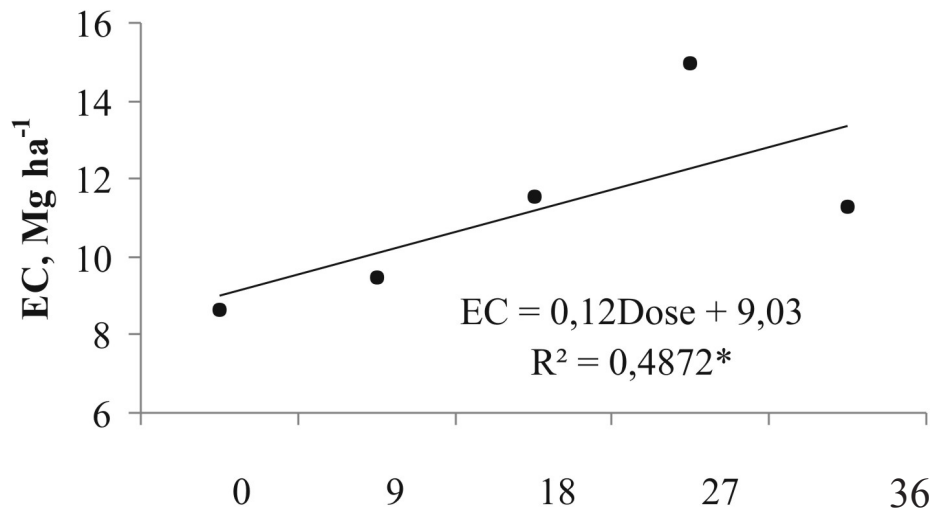

Doses de resíduo de sementes, $\mathrm{Mg} \mathrm{ha}^{-1}$

FIGURA 2 - Estoque de carbono (EC) de um Argissolo Vermelho-Amarelo distrófico em função da aplicação de diferentes doses de resíduo de sementes de goiaba.

\section{CONCLUSÕES}

1-Não há diferença entre os tratamentos em relação à agregação do solo.

2-O maior estoque de carbono orgânico é verificado no solo sob mata nativa.

3-O estoque de carbono no solo e diretamente relacionado à quantidade de resíduo aplicado.

4-Há correlação positiva e significativa entre os índices de agregação e o estoque de carbono orgânico do solo.

\section{REFERÊNCIAS}

ÁLVARO-FUENTES, J.; ARRUÉ, J.L.; GRACIA, R.; LÓPES, M.V. Tillage and cropping intensification effects on soil aggregation: Temporal dynamics and controlling factors under semiarid conditions. Geoderma, Amsterdam, v.145, p.390-396, 2008.

BAYER, C.; LOVATO, T.; DIEKOW, J.; ZANATTA, J.A.; MIELNICZUK, J. A method for estimating coefficients of soil organic matter dynamics based on long-term experiments. Soil \& Tillage Research, Amsterdam, v.91, p.217-236, 2006.

CARDOZO, S.V.; PEREIRA, M.G.; RAVELLI, A.; LOSS, A. Caracterização de propriedades edáficas em áreas sob manejo orgânico e natural na região serrana do Estado do Rio de Janeiro. Semina: Ciências Agrárias, Londrina, v.29, p.515-528, 2008.
CARVALHO, J.L.N.; AVANZI, J.C.; SILVA, M.L.N.; MELLO, C.R.; CERRI, C.E.P. Potencial de sequestro de carbono em diferentes biomas do Brasil. Revista Brasileira de Ciência do Solo, Viçosa, MG, v.34, p.277-289, 2010.

CASTRO FILHO, C.; MUZILLI, O.; PADANOSCHI, A. L. Estabilidade dos agregados e sua relação com o teor de carbono orgânico num Latossolo Roxo distrófico, em função de sistemas de plantio, rotações de culturas e métodos de preparo das amostras. Revista Brasileira de Ciência do Solo, Viçosa, MG, v.22, p.527-538, 1998.

GATTO, A.; BARROS, N.F.; NOVAIS, R.F.; SILVA, I.R.; LEITE, H.G.; LEITE, F.P.; VILLANI, E.M.A. Estoques de carbono no solo e na biomassa em plantações de eucalipto. Revista Brasileira de Ciência do Solo, Viçosa, MG, v.34, p.1.069-1.079, 2010.

KEMPER, W.D.; CHEPIL, W.S. Size distribution of aggregates. In: BLACK, C.A. ed. Methods of soil analysis. Madison: American Society of Agronomy, 1965. p.449-510.

KUSDRA, J.F.; MOREIRA, D.F.; SILVA, S.S.; ARAÚJO NETO, S.E.; SILVA, R.G. Uso de coprólitos de minhoca na produção de mudas de mamoeiro. Revista Brasileira de Fruticultura, Jaboticabal, v.30, p.492-497, 2008.

LEONEL, S.; DAMATTO JUNIOR, E.R. Efeitos do esterco de curral na fertilidade do solo, no estado nutricional e na produção da figueira. Revista Brasileira de Fruticultura, Jaboticabal, v.30, p.534-539, 2008 . 
LOSS, A.; PEREIRA, M.G.; SCHULTZ, N.; ANJOS, L.H.C.; SILVA, E.M.R. Atributos químicos e físicos de um Argissolo Vermelho-Amarelo em sistema integrado de produção agroecológica. Pesquisa Agropecuária Brasileira, Brasília, v.44, p. 68-75, 2009.

MARTINS, M.R.; CORÁ, J.E.; JORGE, R.F.; MARCELO, A.V. Crop type influences soil aggregation and organic matter under no-tillage. Soil \& Tillage Research, Amsterdam, v. 104, p.22-29, 2009.

MATOS, E.S.; MENDONÇA, E.S.; LEITE, L.F.C.; GALVÃO, J.C.C. Estabilidade de agregados e distribuição de carbono e nutrientes em Argissolo sob adubação orgânica e mineral. Pesquisa Agropecuária Brasileira, Brasília, v.43, p.1.221-1.230, 2008.

NATALE, W.; COUTINHO, E. L. M.; BOARETTO, A. E.; PEREIRA, F. M. Goiabeira: calagem e adubação. Jaboticabal: FUNEP, 1996. 22 p.

RAIJ, B. van; ANDRADE, J. C.; CANTARELLA, H.; QUAGGIO, J. A. Análise química para avaliação da fertilidade de solos tropicais. Campinas: Instituto Agronômico, 2001. 285p.

SALTON, J.C.; MIELNICZUK, J.; BAYER, C.; BOENI, M.; CONCEIÇÃO, P.C.; FABRÍCIO, A.C.; MACEDO, M.C.M.; BROCH, D.L. Agregação e estabilidade de agregados do solo em sistemas agropecuários em Mato Grosso do Sul. Revista Brasileira de Ciência do Solo, Viçosa, MG, v.32, p.11-21, 2008.
SORRENTI, G.B.; FACHINELLO, J.C.; CASTILHOS, D.D.; BIANCHI, V.J.; MARANGONI, B. Influência da adubação orgânica no crescimento de tangerineira cv clemenules e nos atributos químicos e microbiológicos do solo. Revista Brasileira de Fruticultura, Jaboticabal, v.30, p.1.129-1.135, 2008.

SOUZA, E.D.; COSTA, S.E.V.G.A.; ANGHINONI, I.; CARVALHO, P.C.F.; ANDRIGUETI, M. CAO, E. Estoque de carbono orgânico e nitrogênio no solo em sistema de integração lavoura-pecuária em plantio direto, submetido a intensidades de pastejo. Revista Brasileira de Ciência do Solo, Viçosa, MG, v.33, p.1829-1836, 2009.

SOUZA, H.A.; NATALE, W.; ROZANE, D.E. Avaliação agronômica da aplicação do resíduo da indústria processadora de goiabas em pomar comercial de goiabeiras. Revista Brasileira de Ciência do Solo, Viçosa, MG, v.35, n.3, p. 969-979, 2011.

VASCONCELOS, R.F.B.; CANTALICE, J.R.B.; OLIVEIRA, V.S.; COSTA, Y.D.J.; CAVALCANTE, D.M. Estabilidade de agregados de um Latossolo Amarelo distrocoeso de tabuleiro costeiro sob diferentes aportes de resíduos orgânicos da canade-açúcar. Revista Brasileira de Ciência do Solo, Viçosa, MG, v.34, p.309-316, 2010. 